\title{
The Validity of Alvarado Score in Diagnosis of Acute Appendicitis among Sudanese Patients
}

\section{Mohanad Abdelrahim ${ }^{1 *}$, Randa Khair ${ }^{2}$ and Kamal Elsiddig ${ }^{2}$}

${ }^{1}$ Department of Human Anatomy, Faculty of Medicine, University of Khartoum, Khartoum, Sudan

${ }^{2}$ Department of Surgery, Faculty of Medicine, University of Khartoum, Khartoum, Sudan

\section{Abstract \\ Background}

Acute appendicitis is the most common cause of an acute abdomen in young adult with a life time risk of about $6 \%$ and appendectomy is the most frequently performed urgent abdominal operation. Diagnosis of acute appendicitis is clinical, the most widely used clinical scoring system is the Alvarado score also known by the acronym mantrels. A decision to operate depending on clinical suspicion only lead to removal of a normal appendix in $15-30 \%$ of cases

\section{Objectives}

To Measure the diagnostic accuracy of Alvarado score as rule in score at cut point of 7 and Assessment of the rule of application of the score in reduction of negative appendectomy.

\section{Methods}

This study is designed as descriptive cross sectional and includes 84 patients whom are admitted as a case of acute appendicitis by surgical emergency unit, Alvarado score was calculated for each patient. Data is analysed using SPSS.

\section{Results}

Negative appendectomy was found in $7.1 \%$ of patients, all were Alvarado score below $7.37 \%$ of overall patients had complicated appendix. At cut point 3 of the score no inflamed appendix was found and at cut of point 7 no normal appendix was found. Elevated temperature was found negative in $43.6 \%$ of positively inflamed appendix.

\section{Conclusion and recommendations}

At cut point of 7 Diagnostic accuracy of Alvarado score is $100 \%$ (all patients at or above 7 have positive surgical appendicitis). $43 \%$ of those with positive appendicitis have no fever. Health education is required to improve and ensure early detection of appendicitis and decrease the high percentage of complicated appendix. Application of Alvarado score may decrease negative appendectomy. Alvarado score require revision and modification to include only high sensitive and specific clinical symptoms and signs and also it includes left shift of Neutrophil maturation, which is not routinely done in many laboratories.

Keywords: Alvarado score; Acute appendicitis; Sudanese patients; Complicated appendixg

\section{Introduction}

\section{Literature review}

Acute Appendicitis is the most common abdominal emergency in both developed and developing countries. Approximately $6 \%$ of the population will suffer from acute appendicitis during their life time in Sudan it was found to be $63 \%$ of overall patients presented as acute abdomen [1-5].

\section{Aetiology of acute appendicitis}

There is no unifying hypothesis regarding the aetiology of acute appendicitis. Decreased dietary fibre and increased consumption of refined carbohydrates may be important. The incidence of appendicitis is lowest in societies with a high dietary fibre intake. In developing countries that are adopting a more refined western-type diet, the incidence continues to rise. This is in contrast to the dramatic decrease in the incidence of appendicitis in western countries observed in the past 30 years. No reason has been established for these paradoxical changes; however, improved hygiene and a change in the pattern of childhood gastrointestinal infection related to the increased use of antibiotics may be responsible. While appendicitis is clearly associated with bacterial proliferation within the appendix, no single organism is responsible. A mixed growth of aerobic and anaerobic organisms is usual. The initiating event causing bacterial proliferation is controversial. Obstruction of the appendix lumen has been widely held to be important, and some form of luminal obstruction, either by a facecloth or a stricture, is found in the majority of cases. A facecloth is composed of insisted faecal material, calcium phosphates, bacteria and epithelial debris. Rarely, a foreign body is incorporated into the mass. The incidental finding of a facecloth is a relative indication for prophylactic appendectomy [6,7]. The incidence of acute appendicitis was maximum in the second and third decades of life (59.2\% patients at $16-29$ years $9 \&$ its complications more in young children \& the elderly. Acute appendicitis is a clinical diagnosis and no laboratory or radiological tests are 100\% accurate and there are many symptoms and signs that commonly overlap with other diagnosis. The differential diagnosis differs in patients of

*Corresponding author: Mohanad Khadil ali abdelrahim, University of Khartoum, khartoum, Sudan, E-mail: mohanadkhalid91@gmail.com

Received October 15, 2015; Accepted December 30, 2015; Published January 07, 2016

Citation: Abdelrahim M, Khair R, Elsiddig K (2016) The Validity of Alvarado Score in Diagnosis of Acute Appendicitis among Sudanese Patients. Surgery Curr Res 6 : 257. doi:10.4172/2161-1076.1000257

Copyright: (c) 2016 Abdelrahim M, et al. This is an open-access article distributed under the terms of the Creative Commons Attribution License, which permits unrestricted use, distribution, and reproduction in any medium, provided the original author and source are credited. 
different ages; in women, additional differential diagnoses are diseases of the female genital tract and delay in diagnosis and management may increase the morbidity \& costs. Lots of efforts have been directed toward early diagnosis and treatment of acute appendicitis. A number of scoring systems have been used for aiding in early diagnosis of acute appendicitis and its prompt management. Scoring systems are valuable and valid instruments for decimating between acute appendicitis and nonspecific abdominal pain. One of the scoring systems is the Alvarado Scoring System which is purely based on history, clinical examination and few laboratory tests and is very easy to apply.

\section{Background information}

Acute appendicitis is the most common cause of an acute abdomen in young adult with a life time risk of about $6 \%$ [8] and appendectomy is the most frequently performed urgent abdominal operation.

Symptoms of appendicitis overlap with a number of other conditions making diagnosis a challenge, particularly at an early stage of presentation [8].

The diagnosis of acute appendicitis is essentially clinical however A number of clinical and laboratory -based scoring systems have been devised to assist diagnosis. the most widely used is the Alvarado score also known by the acronym MANTRELS, for the diagnosis of acute appendicitis as based on symptoms, signs and diagnostic tests in patients presenting with suspected acute appendicitis.

\section{Problem statement}

A decision to operate depending on clinical suspicion only lead to removal of a normal appendix in 15- $30 \%$ of cases [7].

the validity of Alvarado score in certain patient groups and at different cut points is still unclear however it was found to be useful diagnostic 'rule out' score at a cut point of 5 for all patient groups. The score is well calibrated in men, inconsistent in children and overpredicts the probability of appendicitis in women across all strata of risk [8] but still unclear is it valid as rule in score at a cut point of 7 .

\section{Justification}

in developing countries where there are no facilities to do imaging as abdominal ultrasound or contrast enhanced CT-examination in patient in whom there is diagnostic uncertainty the decision to operate depend on clinical suspicion

Thus the aim of this study is to determine the validity of Alvarado score in diagnosis of acute appendicitis and reduction of negative appendectomy

\section{Objectives}

General objective: To assess the diagnostic validity of Alvarado score in diagnosis of acute appendicitis at different cut points.

Specific objective: Measure the diagnostic accuracy of Alvarado score as rule in score at cut point of 7 . Asses the rule of application of Alvarado scores in reduction of negative appendectomy.

\section{Methodology}

prospective observational study of adult patients with suspected appendicitis comprising consecutive patients labelled by surgical emergency unit as acute appendicitis and going to have appendectomy $(\mathrm{N}=84)$ who gave a consent to be included in the study with exclusion of Patients refused to participate or had bad reports or operation sheets.
Patients of both sexes and all age groups, except those younger than 10 years, presented with pain in the right lower quadrant or paraumbilical pain shifting to the right iliac fossa and those who were clinically diagnosed as cases of acute appendicitis were included in the study and their Alvarado scores calculated Sample was classified into three groups according to their Alvarado score:

Group 1: comprising patients with Alvarado score $(1,2,3)$

Group 2: comprising patients with Alvarado score $(4,5,6)$

Group 3: comprising patients with Alvarado score (7, 8, 9, and 10)

The decision for admission and surgical intervention was made by the surgeon independent of the score and was based on patients' history and clinical examination

Gross operative findings are considered the final diagnosis of acute appendicitis and were classified based on surgeon comment into:

Positive inflammation: macroscopic appearance of red appendix

Negative inflammation: There was no macroscopic appearance of inflammation

Complicated appendix: when ruptured appendix or appendicular mass was found

Database management and analysis was performed using the Statistical Package for the Social Science (SPSS), version 20.

Written consent from emergency department unit was taken.

\section{Results}

Total number of 85 patients were included in this study 54 were male $(64.3 \%)$ and $30(35.7 \%)$ were female there was no significant difference in inflammation table (2), the majority of the patients in the third decade the mean age was (26.19) (Figure 1), (Tables 1 and 2).

$70 \%$ of patients had Alvarado sore 7 or above the median of Alvarado score was 7, there was $1 \%$ had Alvarado score below 4 (low score) (Figure 2).

Negative appendectomy was found in 6 patients $(7.1 \%)$, all were Alvarado score below 7 , while 23 patients ( $37 \%$ of overall patients ) had complicated appendix (22) had score 7 or above and only 1 patient had score 6 (figure 3 ) shows the status of appendix at time of operation (Figure 3).

At cut point 3 of the score no inflamed appendix was found and at cut of point 7 no normal appendix was found, at score 4, 5, 6 there was 24 patients (28\% of all patients) among whom there was 19 patients (79.16\%) had inflamed appendix (Table 3).

\section{Discussion}

Negative appendectomy was $9 \%$ almost the same figure noted at Pakistan in [2] study but the universal negative appendectomy is 15$30 \%$, our low rate it may be due to delaying in reaching the hospital which make the clinical picture of acute appendicitis more clear and raise Alvarado score of our patients, also our dependence on surgical observations instead of histopathological confirmation do play role in this low rate. The median of Alvarado score was 7, 30\% had score below 7 ( 25 patients, $27 \%$ of our patients had complicated appendix. The diagnostic predictive value of Alvarado score was $100 \%$, negative appendectomy at high score group was found .0\%. While it was found to be $90 \%, 83.79 \%$ at [2] study and [7] study respectively the difference may be due to defect in our selection of sample which wasn't include all 
Citation: Abdelrahim M, Khair R, Elsiddig K (2015) The Validity of Alvarado Score in Diagnosis of Acute Appendicitis among Sudanese Patients. Surgery Curr Res 6: 257. doi:10.4172/2161-1076.1000257
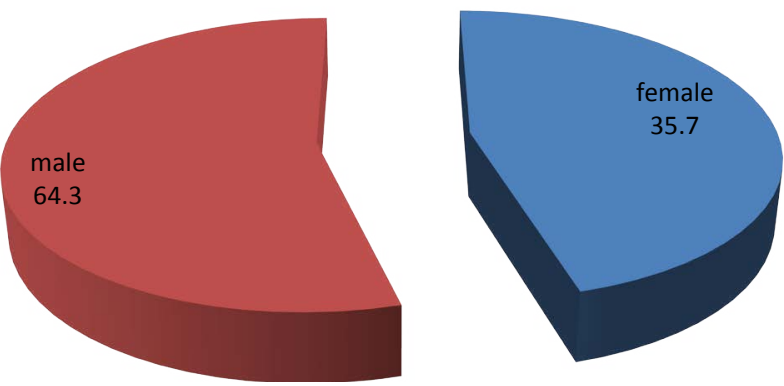

Figure 1: Gender Percentage.

\begin{tabular}{|c|c|c|c|}
\hline \multirow{2}{*}{ Appendix } & \multicolumn{2}{|c|}{ Gender } & \multirow{2}{*}{ Total } \\
\hline & male & female & \\
\hline positive & $\begin{array}{c}51 \\
94.40 \%\end{array}$ & $\begin{array}{c}27 \\
90.00 \%\end{array}$ & $\begin{array}{c}78 \\
92.90 \%\end{array}$ \\
\hline negative & $\begin{array}{c}3 \\
5.60 \%\end{array}$ & $\begin{array}{c}3 \\
10.00 \%\end{array}$ & $\begin{array}{c}6 \\
7.10 \%\end{array}$ \\
\hline Total & $\begin{array}{c}54 \\
100.00 \%\end{array}$ & $\begin{array}{c}30 \\
100.00 \%\end{array}$ & $\begin{array}{c}84 \\
100.00 \%\end{array}$ \\
\hline Pearson Chi-Square & Value df $\begin{array}{l}\text { Asymp. } \\
\text { (2-sided) }\end{array}$ & $\begin{array}{l}\text { Sig. Exact Sig. } \\
(2 \text {-sided })\end{array}$ & $\begin{array}{l}\text { Exact Sig. } \\
\text { (1-sided) }\end{array}$ \\
\hline
\end{tabular}

Table 1: Inflamed appendix against gender difference.

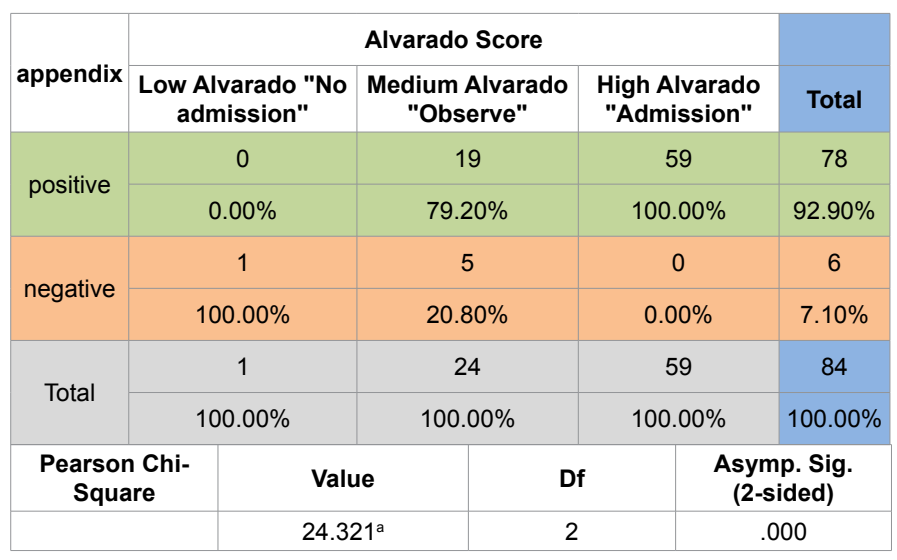

$P$ value was 0.000

Table 2: Alvarado score groups and appendix status at time of operation.

acute abdomen patients. At cut off point of 3 Alvarado score was found to be accurate rule out score in our study which meet the international report [1]. Fever wasn't found in $43 \%$ of positively inflamed appendix, the sensitivity was 63.8 and specificity was 39.2 at [5-10] it was not a constant feature of appendicitis.

\section{Conclusion}

In conclusion diagnostic accuracy of Alvarado score is found to be $100 \%$ at cut point of 7 , because all patients with Alvarado score 7 or above have positive surgical appendicitis. $43 \%$ of those with positive appendicitis have no fever. No difference regarding age and gender distribution.
- Low Alvarado "No admission" Medium Alvarado "Observe"

High Alvarado "Admission"

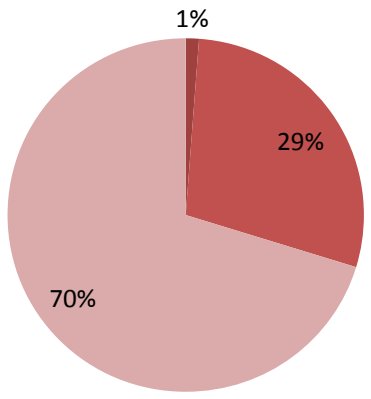

Figure 2: Alvarado score found.

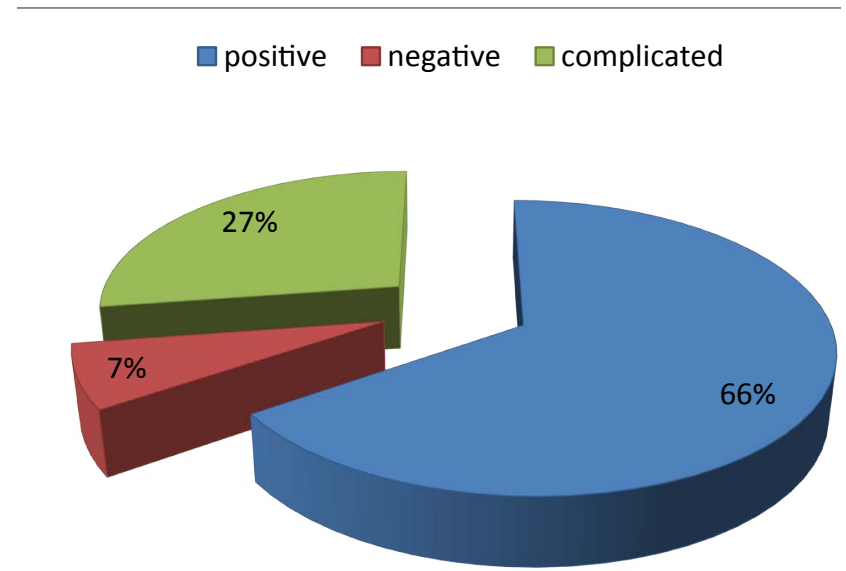

Figure 3: Appendix as seen by surgeon.

\begin{tabular}{|c|c|c|c|}
\hline \multirow{2}{*}{ Elevated temperature } & \multicolumn{2}{|c|}{ Appendix } & \multirow{2}{*}{ Total } \\
\cline { 2 - 4 } & $+\mathrm{ve}$ & $-\mathrm{ve}$ & \\
\hline +ve & 44 & 2 & 46 \\
\hline & $56.4 \%$ & $33.3 \%$ & $54.8 \%$ \\
\hline -ve & 34 & 4 & 38 \\
\hline & $43.6 \%$ & $66.7 \%$ & $45.2 \%$ \\
\hline
\end{tabular}

\begin{tabular}{|c|c|c|c|c|c|}
\hline $\begin{array}{c}\text { Chi-Square Tests } \\
\text { Square }\end{array}$ & Value & df & $\begin{array}{c}\text { Asymp. Sig. } \\
\text { (2-sided) }\end{array}$ & $\begin{array}{c}\text { Exact Sig. } \\
\text { (2-sided) }\end{array}$ & $\begin{array}{c}\text { Exact Sig. } \\
\text { (1-sided) }\end{array}$ \\
\hline & $1.198 a$ & 1 & 0.274 & 0.403 & 0.252 \\
\hline
\end{tabular}

Table 3: Elevated temperature was found negative in $43.6 \%$ of positively inflamed appendix.

\section{Recommendations}

1. Another study with histopathological confirmation is required to cover our weak points and ensure the diagnostic accuracy of Alvarado score.

2. Alvarado score require revision and modification to include 
Citation: Abdelrahim M, Khair R, Elsiddig K (2015) The Validity of Alvarado Score in Diagnosis of Acute Appendicitis among Sudanese Patients. Surgery Curr Res 6: 257. doi:10.4172/2161-1076.1000257

Page 4 of 4

only high sensitive and specific clinical symptoms and signs and also it includes left shift of Neutrophil maturation, which is not routinely done in many laboratories.

3. Health education is required to improve and ensure early detection of appendicitis and decrease the high percentage of complicated appendix.

4. Application of Alvarado score is helpful in decreasing negative appendectomy rate.

\section{References}

1. Carachi R (2009) Bailey And Love's Short Practice Of Surgery 25Th Edition Scottish Medical Journal 54.1: 48.

2. Dholia, Ram K, Shaik MS (2009) Evaluation Of Alvarado Score In Diagnosis Of Acute Appendicitis. Pakistan journal of surgery 25: $159-163$.

3. Douglas CD (2000) Randomised Controlled Trial Of Ultrasonography In Diagnosis Of Acute Appendicitis, Incorporating The Alvarado Score. BMJ 321: 919.
4. Doumi EBA, Mohammed MI (2009) Acute Bbdomen At El Obeid Hospital,Western Sudan. Sudan Journal of Medical Sciences 4:

5. Idris SA, Shalayel MH, Awad YO, Idris TA, Ali AQ et al. (2009) The Sensitivity And Specificity Of The Conventional Symptoms And Signs In Making A Diagnosis Of Acute Appendicitis. Sudan Journal of Medical Sciences 4:

6. Khan I, ur Rehman A(2005) Application of alvarado scoring system in diagnosis of acute appendicitis. J Ayub Med Coll Abbottabad 17: 41-44.

7. Kailash S, Shyam G, Pinki P (2008) Application of Alvarado Scoring System in Diagnosis of Acute Appendicitis. JK SCIENCE 10 :

8. Ohle R, O'Reilly F,O'Brien K K , Faheyet T, Dimitrov BD (2011) The Alvarado Score For Predicting Acute Appendicitis: A Systematic Review. BMC Medicine 9: 139.

9. Sanei B, Mahmoodieh M, Hosseinpour M (2009) Evaluation of validity of Alvarado scoring system for diagnosis of acute appendicitis. Pak J Med Sci 25: 298-301.

10. Talukder DB, and Siddiq AKMZ (2009) Modified Alvarado Scoring System In The Diagnosis Of Acute Appendicitis. J. Armed Forces Med. Coll 5: 